\title{
Influence of Family Violence on the Marital Quality in Pakistani Muslims: Role of Personal Factors
}

\author{
Aisha Perveen * and Sadia Malik \\ Department of Psychology, University of Sargodha, Sargodha 40100, Pakistan; drsadiamalik13@gmail.com \\ * Correspondence: fatimakhan786887@gmail.com
}

Received: 29 June 2020; Accepted: 10 September 2020; Published: 15 September 2020

\begin{abstract}
The purpose of this study was to examine the role of self-compassion and religiosity in marital quality among married Pakistani Muslims in abusive or violent relationships. The study aimed at exploring religion and self-kindness as protective factors that could save and strengthen marital relationships despite family violence. Four standardized scales, Family Violence Scale, Self-Compassion Questionnaire, Centrality of Religiosity Questionnaire and Marital Quality Questionnaire were used for data collection from married Muslims of Punjab $(N=600)$. Analysis was carried out with PROCESS macro for SPSS which revealed that religiosity moderated between family violence and marital quality and buffered its negative effects. Furthermore, self-compassion mediated family violence and marital quality influencing its quality. These findings would benefit researchers, and other practitioners who work with married adults helping them work out their abusive differences improving marital quality of life.
\end{abstract}

Keywords: family violence; protective factors; centrality of religiosity; religiosity; marital quality; self-compassion; Pakistani Muslims

\section{Introduction}

All around the world, marital relationships are fundamental and basic intimate bonds between two people. Beginning with the second half of the twentieth century, studies on marriage focused on understanding the dynamics of marital functioning that included satisfaction, violence and health hazards in relationships (Carvalho-Barret et al. 2009). Numerous studies have examined the importance of religiosity (Aman et al. 2019) and self-compassion (Janjani et al. 2017), and its impact on marital relationships; however, there are limited studies (if any) carried out in Pakistan to understand the role of healing factors in marital quality (Hood et al. 2018); particularly when family violence ensues. As a matter of fact, the less visible, but most prevalent forms of violence are day-to-day sufferings when violence festers in marriage. In developing countries, family violence has become a serious concern for women and their health and their family's health. World Health Organization (1996) describes family violence as " ... violent, threatening or other behavior by a person, men or women, that coerces or controls a member of the person's family (the family member), or causes the family member to be fearful (pp. 5-6)". Cost of family violence includes physical and psychological health, relationship integrity, and quality of life, and since this matter in developing countries is culturally sensitive and private, researchers reluctantly and rarely probe or address it, e.g., in Pakistan, people are likely to maintain their positive image, and express socially desirable responses about their lives and families (Henning et al. 2005), nevertheless $22 \%$ of women face physical abuse, $27 \%$ sexual violence, and $60 \%$ experience serious acts of psychological violence during their marital life (Zakar et al. 2012), compared to the rate of the abuse of women in the US which is approximately two percent per year (Patricia and Nancy 1998). In another study, Khan et al. (2009) conducted a meta-analysis and reported that there is a rate of $30-79 \%$ family violence in Pakistani households. 
Family violence is a serious social and health problem due to its long-lasting harmful effects on women's health, wellbeing and relationships. If relationships are based on any kind of violence, it would ultimately compromise quality in the marital relationship. Marital quality is a subjective evolution of the marriage and is a multidimensional construct associated with three dimensions: marital satisfaction, marital adjustment and relation with in-laws (Kousar and Khalid 2003). Poor marital quality was linked to mental health problems such as stress and depression which may further influence the general quality of life (Karney and Nelson 1995).

Surprisingly, despite suffering, people often do not leave their spouses, and studies have shown reasons for that include education, age differences, dowry, economic dependence, and societal pressure etc. (Koenig et al. 2003). Along with other factors that keep spouses together, compassion towards the spouse seems a good candidate, however compassion towards ourselves may be diluted or absent, which could also affect marital relationships. Most of us treat ourselves rather unkindly when bad things happen to us in marriage, and rather than offering sympathy and support as we do to our loved ones, we tend to criticize ourselves, hide from others or ourselves in shame, and get stuck with ideas trying to make sense of what happened to us. Such reactions and behaviors cause personal suffering and can influence interpersonal relationships. Studies report that when individuals see themselves as worthy and accept the ability to be happy and healthy, their ability to maintain quality romantic relationships is preserved (Collins and Read 1990; Hazan and Shaver 1990; Mikulincer and Shaver 2003).

Fortunately, our hardwired capacity to respond to suffering in a soothing, healing way is self-compassion (Neff 2011). Self-compassionate people have three components: self-kindness, a sense of common humanity, and mindfulness when confronting negative self-relevant thoughts and emotions. Self-compassion is truly the change of negativity about worst situations into positive thinking and reactions (Neff 2003b). Williams (2015) came up with the fact that self-compassion and self-forgiveness help people to come out of their shame and avoidant behaviors. Self-compassion is also linked with happiness and health of married couples which ultimately predict the quality of a relationship (Neff and Beretvas 2013).

Religion is yet another significant protective factor for married couples to maintain their relationships. One of the central points in Islam is to maintain social and marital life, by asking followers to be nurturing when bonded in family life rather superficially holding marital obligations. Similarly, practicing religious activities like praying, recitation of Quran etc. are linked with marital well-being (Alsharif et al. 2011).

It is reported that religious people are happier and more satisfied in their relationship (Stafford 2016) and have stable married lives compared to non-religious married couples (Langlais and Schwanz 2017). Similarly, Austin et al. (2018) report, religious couples tend to view divorce negatively, and are willing to sacrifice for their spouses to maintain happy marriages. Religious commitment and religious practice strengthens and promotes marital satisfaction in couples living in urban areas (Aman et al. 2019).

In Pakistan, research in exploring protective factors of family violence is still in its embryonic phase, because this matter is culturally sensitive and private and therefore victims are unlikely to share information or tell "outsiders" about their issues (Ayyub 2000). Family violence does not occur as an isolated incident in the lives of abused married women, rather it recurrently causes damage not only on the victims, but to their families and on society as whole (Carvalho-Barret et al. 2009). These untold stories of family violence ranging from psychological torture to physical violence tends to be harmful for physical and mental health of married adults and poison for their relationships further impeding their marital quality. Marital quality is an important and integral aspect of family life playing important role in the married adults' health and wellbeing. In Pakistani patriarchal society, usually married adults have to continue abusive relationships despite poor marital quality, due to some cultural and other reasons. Studies have proved that married adults with abusive partners utilize a variety of coping strategies to deal with family violence. A majority of women (97\%) reported that spirituality or God and turning to their religion was a source of strength or comfort for them (Gillum et al. 2006). Another important factor was self-compassion which protects people against stressful events 
and is very important for an individual's mental health (Allen and Leary 2010). These protective factors do not necessarily eliminate the stresses and strains but help to see the problem in a different context.

\section{Hypotheses}

Main objective of the present study was to analyze the influence of family violence on the marital quality of married Muslim adults living in Pakistan. Further, it was aimed to investigate the role of personal factors (i.e., religiosity and self-compassion) in protecting against family violence and improving marital quality of married adults. Another objective was to explore gender differences in terms of these personal factors, marital quality and family violence. Based upon these objectives, the following hypotheses were formulated:

1. Religiosity is likely to moderate the relationship between family violence and marital quality of Muslim married adults of Pakistan.

2. Self-compassion is likely to mediate the relationship between family violence and marital quality of Muslim married adults of Pakistan.

3. Significant gender difference would be found in terms of religiosity, marital quality, self-compassion and family violence.

\section{Conceptual Framework}

Hypothesis 1. Model (see Figure 1).

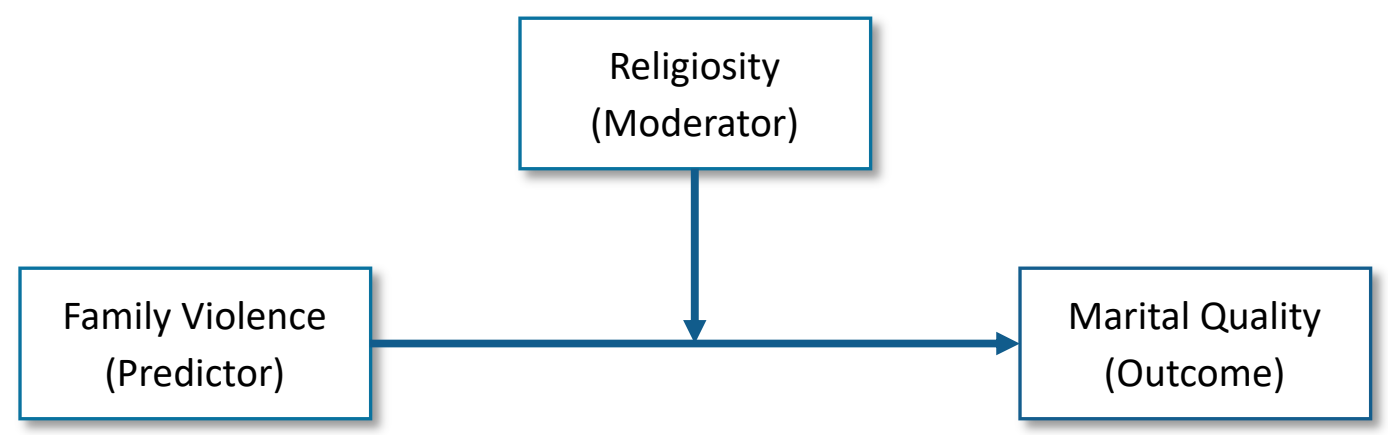

Figure 1. A schematic model of religiosity and its moderation between family violence and marital quality.

Hypothesis 2. Model (see Figure 2).

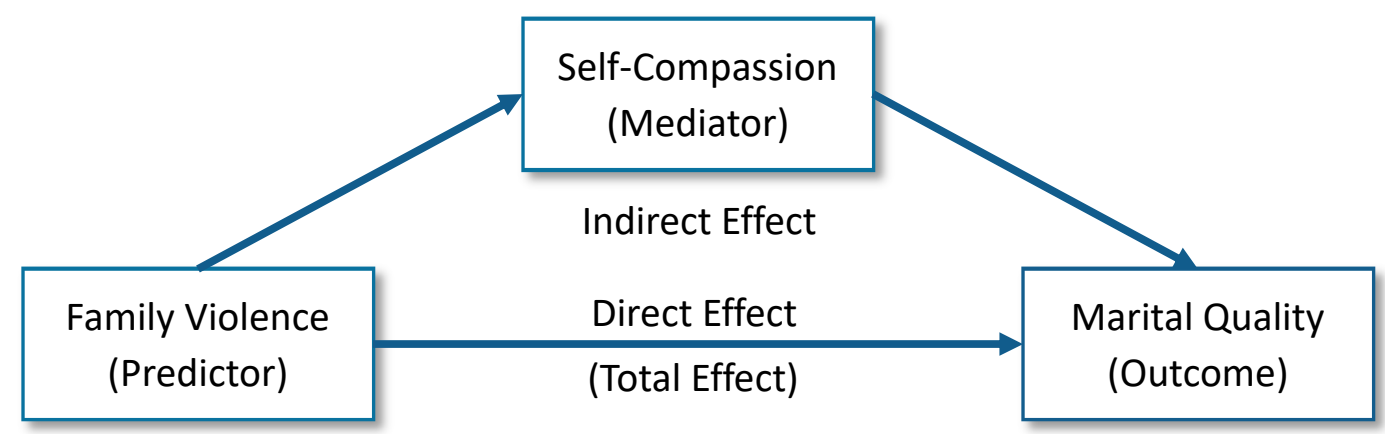

Figure 2. Schematic representation of the mediating role of self-compassion between family violence and marital quality. 


\section{Method}

The present study was designed to examine the role of self-compassion and religiosity in marital quality among married Pakistani Muslims in abusive or violent relationships. Detail of the sample, instruments and procedure is given below:

\subsection{Participants}

The present study consisted of a purposive sample of $262(44 \%)$ married men and $338(56 \%)$ women $(n=600)$ recruited from various cities of the Punjab. Participants ages ranged from 19 to 51 years $(M=35.90, S D=7.30)$, with a minimum of one year of marriage. Since the sample was purposive, we used those married adults who were facing some kind of family violence in their lives.

\subsection{Instruments}

Family Violence Scale (FVS). This is a family violence scale for married adults (Perveen and Malik 2019) a 37-item scale where each item is rated on a 5-point Likert-type scale ranging from 1 (Never) to 5 (Always). This scale is divided into five subscales, which include, 6-item Sexual Abuse subscale (e.g., "I am forced to make those sexual acts which I don't like"), 10-item Social Degradation subscale (e.g., "I am not allowed to meet people"), 5-item Economical Assault subscale (e.g., "My basic economical need are not fulfilled "), 11-item Psychological Torture subscale (e.g., "I am insulted") and 5-item Physical Violence subscale (e.g., "I am dragged by pulling my arms"). Higher score on the scale and subscales represent greater family violence. The internal consistency of the scale measured $(\alpha=0.96)$ previously (Perveen and Malik 2019) and obtained reliability is $(\alpha=0.94)$ in this study (see Table 1).

Self-Compassion Questionnaire (SCS). Neff (2003a) developed a 26-item self-report questionnaire on self-compassion that rates each item on a 5-point Likert-type scale ranging from 1 (Almost Never) to 5 (Almost Always). This scale measures the extent to which people engage in self-kindness versus self-judgment, common humanity versus isolation, and mindfulness versus over identification through five subscales, which include, 5-item Self-Kindness subscale (e.g., "I try to be understanding and patient toward aspects of my personality"), the 5-item Self-Judgment subscale (e.g., "I'm disapproving and judgmental about my own flaws and inadequacies"), the 4-item Common Humanity subscale (e.g., "I try to see my failings as part of the human condition"), the 4-item Isolation subscale (e.g., "When I think about my inadequacies it tends to make me feel more separate and cut off from the rest of the world"), the 4-item Mindfulness subscale (e.g., "When something painful happens I try to take a balanced view of the situation"), and the 4-item Over-Identification subscale (e.g., "When I'm feeling down I tend to obsess and fixate on everything that's wrong."). The internal consistency was reported as $\alpha=0.92$, however obtained reliability coefficient in this study was $\alpha=0.71$ (see Table 1).

Centre of Religiosity Questionnaire-15 (CRS-15). This is a measure of the "centrality, importance or salience of religious meanings in personality" (Huber and Huber 2012) and is suitable for Abrahamic religions including Judaism, Christianity and Islam. The scale consists of fifteen items and divided into five subscales: intellect-3 items (e.g., how often do you think about religious issues?), ideology-3 items (e.g., in your opinion, how probable is it that a higher power really exists), public practice-3 items (e.g., how often do you take part in religious services?), private practice- 3 items (How often do you pray?) and religious experience-3 items (e.g., how often do you experience situations in which you have the feeling that God or something divine is present?). In three studies reliabilities of CRS-15 ranged from 0.92 to 0.96 (Huber 2007) and for the current study ( $\alpha=0.75$ ) see Table 1 below.

Marital Relationship Questionnaire (MRQ). Kousar and Khalid (2003), developed MRQ based on Burgess Marriage Adjustment Schedule (Burgess and Locke 1960), and it consisted of 48 items. The scale has three dimensions of marital relationship which collectively define marital quality. These dimensions are comprised of 22 items of Marital Adjustment subscale (e.g., "can you openly discuss 
your opinion with your husband?"), 21 items of Marital Satisfaction subscale (e.g., "do you think your marital life is happy life?), and 5 items of Relationship with In-laws subscale (e.g., "do you help your in-laws in the time of need?"). These three dimensions collectively determine the quality of marital relationship and higher score represents greater marital quality. Obtained reliability of the scale in this case was $\alpha=0.84$. See Table 1 below.

Table 1. Descriptive statistics, reliability coefficients and inter-correlation among scales.

\begin{tabular}{|c|c|c|c|c|c|c|c|c|c|}
\hline No. & Variable & $M(S D)$ & $\alpha$ & $S$ & K & 1 & 2 & 3 & 4 \\
\hline 1. & Family Violence & $\begin{array}{c}91.14 \\
(26.00)\end{array}$ & 0.94 & -0.05 & -0.80 & - & -0.08 & $-0.40 *$ & -0.38 * \\
\hline 2. & Self-Compassion & $\begin{array}{l}36.66 \\
(6.42)\end{array}$ & 0.71 & -0.54 & 0.19 & & - & $0.31 *$ & 0.41 * \\
\hline 3. & Religiosity & $\begin{array}{l}56.58 \\
(8.10)\end{array}$ & 0.75 & -0.20 & -0.10 & & & - & $0.45^{*}$ \\
\hline 4. & Marital Quality & $\begin{array}{l}127.80 \\
(23.52)\end{array}$ & 0.84 & 0.26 & -0.91 & & & & - \\
\hline
\end{tabular}

\subsection{Procedure}

Permission for data collection was sought from the departmental head and then from different Health Care Centers of selected cities. For reasons involving sensitivity of the topic, these centers were approached for obtaining access to participants who were facing some form of family violence. Those married adults who came to seek healthcare in these clinics were requested to provide information on the questionnaire after receiving their consent. This approach was particularly indispensable because approaching women who face violence at home could not be sought at their residence for a number of reasons from living in joint families to strong patriarchal values that could have prevented us from reaching them for testing. All participants were briefed about the study and confidentiality and anonymity of information was assured. A packet that consisted of demographic sheet and scales mentioned above were distributed to the participants. There was no restriction of time for the completion of scales. As a gesture of gratitude, at the individual level for some participants a "listening ear" was provided to counsel those, if such a request was made.

\section{Results}

Table 1 presents mean, standard deviations, reliabilities and inter-correlations of scales used in the study and indicates that scales had moderate to high internal consistencies. Results revealed significant $(p<0.01)$ negative correlations between family violence and religiosity and marital quality, but not with self-compassion. In addition, self-compassion and religiosity were significantly positively correlated $(p<0.01)$; self-compassion and marital quality were significantly $(p<0.01)$ positively related; and finally religiosity and marital quality were also significantly $(p<0.01)$ positively correlated.

Table 2 showed inter-correlations among scales and subscales. Religiosity and its subscales are negatively and significantly $(p<0.01)$ associated with family violence and with all its subscales. Findings revealed that religiosity has positive and significant correlation with all other scales and subscales used in the study except two subscales. These public practice and private practice subscales of religiosity have a positive but non-significant correlation with the self-judgment scale of self-compassion. Self-compassion has a negative relationship with social degradation and economical assault subscale but it has positive and significant $(p<0.01)$ correlation with physical violence. It has negative but non-significant correlation with the total scale of family violence. Furthermore, self-compassion is positively associated with religiosity and marital quality. Reliabilities of all scales and subscales showed moderate to high internal consistency ranging from 0.69 to 0.94 . 
Table 2. Inter-correlation among scales and subscales.

\begin{tabular}{|c|c|c|c|c|c|c|c|c|c|c|c|c|c|}
\hline & Scale/Subscale & $\alpha$ & 1 & 2 & 3 & 4 & 5 & 6 & 7 & 8 & 9 & 10 & 11 \\
\hline 1 & Family Violence & 0.94 & - & & & & & & & & & & \\
\hline 2 & Sexual Abuse & 0.81 & $0.84 * *$ & - & & & & & & & & & \\
\hline 3 & Social degrade & 0.91 & $0.85^{* *}$ & $0.66^{* *}$ & - & & & & & & & & \\
\hline 4 & Economical A & 0.79 & $0.82 * *$ & $0.63^{* *}$ & $0.67^{* *}$ & _- & & & & & & & \\
\hline 5 & Psychological T & 0.86 & $0.85^{* *}$ & $0.67^{* *}$ & $0.53 * *$ & $0.60 * *$ & - & & & & & & \\
\hline 6 & Physical Violence & 0.71 & $0.68^{* *}$ & $0.51 * *$ & $0.42 * *$ & $0.49^{* *}$ & $0.57^{* *}$ & - & & & & & \\
\hline 7 & Marital Quality & 0.84 & $-0.38^{* *}$ & $-0.29 * *$ & $-0.46^{* *}$ & $-0.35^{* *}$ & $-0.26^{* *}$ & -0.02 & _- & & & & \\
\hline 8 & M Adjustment & 0.89 & $-0.48^{* *}$ & $-0.40 * *$ & $-0.57 * *$ & $-0.44^{* *}$ & $-0.31^{* *}$ & $-0.08^{*}$ & $0.94^{* *}$ & - & & & \\
\hline 9 & M Satisfaction & 0.73 & $-0.16^{* *}$ & -0.07 & $-0.25^{* *}$ & $-0.14^{* *}$ & $-0.14^{* *}$ & 0.06 & $0.86^{* *}$ & $0.64^{* *}$ & - & & \\
\hline 10 & Relation w/in-laws & 0.7 & $-0.18 * *$ & $-0.13 * *$ & $-0.17^{* *}$ & $-0.24 * *$ & $-0.14 * *$ & 0.002 & 0.66 ** & $0.57 * *$ & $0.48^{* *}$ & _- & \\
\hline 11 & Self-Compassion & 0.71 & -0.08 & -0.06 & $-0.16^{* *}$ & $-0.08 *$ & -0.08 & $0.17^{* *}$ & $0.41 * *$ & $0.38^{* *}$ & $0.39 * *$ & $0.24 * *$ & - \\
\hline 12 & Self-Kindness & 0.75 & $-0.20 * *$ & $-0.21 * *$ & $-0.29 * *$ & $-0.16^{* *}$ & $-0.09 *$ & 0.01 & $0.36^{* *}$ & $0.37^{* *}$ & $0.29 * *$ & 0.21 ** & $0.71 * *$ \\
\hline 13 & Self-Judgment & 0.75 & 0.04 & 0.04 & -0.03 & 0.05 & 0.05 & $0.14^{* *}$ & $0.16^{* *}$ & $0.13 * *$ & $0.18^{* *}$ & 0.03 & $0.59 * *$ \\
\hline 14 & Common $\mathrm{H}$ & 0.7 & $-0.20 * *$ & $-0.17 * *$ & $-0.19 * *$ & $-0.19 * *$ & $-0.23 * *$ & 0.08 * & $0.39 * *$ & $0.35^{* *}$ & $0.36 * *$ & $0.23 * *$ & $0.74 * *$ \\
\hline 15 & Isolation & 0.68 & -0.07 & -0.03 & $-0.15^{* *}$ & $-0.12 * *$ & 0.01 & $0.09 *$ & $0.34^{* *}$ & 0.34 ** & $0.26^{* *}$ & $0.25^{* *}$ & 0.58 ** \\
\hline 16 & Mindfulness & 0.72 & -0.04 & -0.05 & -0.06 & -0.02 & -0.07 & $0.10 *$ & $0.24^{* *}$ & $0.17^{* *}$ & $0.27 * *$ & $0.17^{* *}$ & $0.61 * *$ \\
\hline 17 & Over-identification & 0.68 & $0.18^{* *}$ & $0.21 * *$ & $0.15^{* *}$ & $0.15^{* *}$ & 0.07 & $0.25 * *$ & $0.09 *$ & 0.05 & $0.12 * *$ & 0.05 & $0.58^{* *}$ \\
\hline 18 & Religiosity & 0.75 & $-0.40 * *$ & $-0.24 * *$ & $-0.49 * *$ & $-0.34 * *$ & $-0.27 * *$ & $-0.16 * *$ & $0.45^{* *}$ & $0.44 * *$ & $0.40 * *$ & $0.15^{* *}$ & $0.31 * *$ \\
\hline 19 & Intellect & 0.72 & -0.33 ** & -0.19 ** & -0.50 ** & -0.26 ** & $-0.14^{* *}$ & -0.07 & $0.29^{* *}$ & $0.36^{* *}$ & $0.19^{* *}$ & 0.02 & $0.13 * *$ \\
\hline 20 & Ideology & 0.79 & $-0.32 * *$ & $-0.17^{* *}$ & $-0.36^{* *}$ & $-0.29 * *$ & $-0.25^{* *}$ & $-0.13 * *$ & $0.34^{* *}$ & $0.33^{* *}$ & $0.31 * *$ & $0.13^{* *}$ & $0.30 * *$ \\
\hline 21 & Public Practice & 0.76 & $-0.15^{* *}$ & $-0.09 *$ & $-0.18^{* *}$ & $-0.19 * *$ & -0.05 & $-0.13 * *$ & $0.22 * *$ & $0.17^{* *}$ & $0.26^{* *}$ & 0.05 & $0.18 * *$ \\
\hline 22 & Private Practice & 0.7 & $-0.28 * *$ & $-0.19 * *$ & $-0.34 * *$ & $-0.24 * *$ & -0.18 ** & $-0.14 * *$ & $0.34^{* *}$ & $0.31^{* *}$ & $0.34 * *$ & $0.12 * *$ & $0.25 * *$ \\
\hline 23 & Religious Experience & 0.75 & $-0.29 * *$ & $-0.16^{* *}$ & -0.30 ** & $-0.20 * *$ & $-0.31 * *$ & $-0.09 *$ & $0.37^{* *}$ & 0.34 ** & $0.33 * *$ & $0.19^{* *}$ & $0.26 * *$ \\
\hline
\end{tabular}


Table 2. Cont.

\begin{tabular}{|c|c|c|c|c|c|c|c|c|c|c|c|c|c|}
\hline & Scale/Subscale & 12 & 13 & 14 & 15 & 16 & 17 & 18 & 19 & 20 & 21 & 22 & 23 \\
\hline 1 & Family Violence & & & & & & & & & & & & \\
\hline 2 & Sexual Abuse & & & & & & & & & & & & \\
\hline 3 & Social degrade & & & & & & & & & & & & \\
\hline 4 & Economical A & & & & & & & & & & & & \\
\hline 5 & Psychological T & & & & & & & & & & & & \\
\hline 6 & Physical Violence & & & & & & & & & & & & \\
\hline 7 & Marital Quality & & & & & & & & & & & & \\
\hline 8 & M Adjustment & & & & & & & & & & & & \\
\hline 9 & M Satisfaction & & & & & & & & & & & & \\
\hline 11 & Self-Compassion & & & & & & & & & & & & \\
\hline 12 & Self-Kindness & - & & & & & & & & & & & \\
\hline 13 & Self-Judgment & $0.32 * *$ & _- & & & & & & & & & & \\
\hline 14 & Common $\mathrm{H}$ & $0.43 * *$ & $0.32 * *$ & _- & & & & & & & & & \\
\hline 15 & Isolation & $0.39 * *$ & $0.19^{* *}$ & $0.26 * *$ & _ & & & & & & & & \\
\hline 16 & Mindfulness & $0.36 * *$ & $0.25^{* *}$ & $0.37 * *$ & $0.30 * *$ & _- & & & & & & & \\
\hline 17 & Over-identification & $0.19 * *$ & $0.14 * *$ & 0.39 ** & 0.24 ** & $0.23 * *$ & - & & & & & & \\
\hline 18 & Religiosity & $0.29 * *$ & 0.13 ** & $0.27 * *$ & $0.17 * *$ & 0.26 ** & $0.06 * *$ & _ & & & & & \\
\hline 19 & Intellect & $0.18 * *$ & 0.09 * & 0.07 & $0.13 * *$ & $0.09 * *$ & $-0.07 * *$ & $0.76^{* *}$ & _- & & & & \\
\hline 20 & Ideology & $0.20 * *$ & $0.14^{* *}$ & $0.24^{* *}$ & $0.19^{* *}$ & 0.20 ** & $0.17 * *$ & $0.69 * *$ & $0.46^{* *}$ & - & & & \\
\hline 22 & Private Practice & $0.24 * *$ & 0.06 & 0.23 ** & $0.12 * *$ & $0.21 * *$ & 0.10 ** & $0.72 * *$ & $0.36^{* *}$ & $0.41 * *$ & $0.43^{* *}$ & _- & \\
\hline 23 & Religious Experience & 0.20 ** & $0.13^{* *}$ & $0.30 * *$ & 0.12 ** & 0.20 ** & $0.04 * *$ & $0.69^{* *}$ & $0.36^{* *}$ & $0.33 *$ & 0.25 ** & $0.37^{* *}$ & - \\
\hline
\end{tabular}

Notes: Social Degrade (social degradation), Common H (common Humanity), M Adjustment (marital adjustment), M Satisfaction (marital satisfaction), Psychological T (psychological torture), Economical A (economical assault). ${ }^{*} p<0.01, * * p<0.001$ 
Moderation analysis was carried out with PROCESS macro for SPSS (Hayes 2018). Results in Table 3 showed religiosity played a moderating role between family violence and marital quality among Pakistani Muslim married adults. The value of $\mathrm{R}^{2}$ indicates a $26 \%$ of variance in the outcome variable is explained by the predictor with $F(3,596)=69.97, p<0.001$. The value of $\Delta R^{2}$ is 0.01 with $\Delta F(1,596)=10.45, p<0.001$ which explains variance of $1 \%$ by the additional effect of religiosity. The findings revealed that religiosity $(B=1.02, p<0.001)$ is positively associated with marital quality while interaction effect of family violence and religiosity $(B=0.01, p<0.001)$ has significant buffering effect on marital quality. This indicates that the higher the religiosity, the weaker is the negative effect of family violence on marital quality.

Table 3. Moderating role of religiosity between family violence total and marital quality.

\begin{tabular}{cccc}
\hline \multicolumn{3}{c}{ Outcome: Marital Quality } \\
\hline \multicolumn{3}{c}{$\mathbf{9 5 \%}$ CI } \\
\hline Model & $\boldsymbol{B}$ & $\mathbf{L L}$ & $\mathbf{U L}$ \\
\hline (constant) & $129.02^{\dagger}$ & 127.23 & 130.81 \\
Family Violence & $-0.23^{*}$ & -0.29 & -0.16 \\
Religiosity & $1.02^{*}$ & 0.80 & 1.24 \\
Family Violence X Religiosity & $0.01^{\dagger}$ & 0.01 & 0.02 \\
Low & $-0.34^{*}$ & -0.45 & -0.24 \\
Medium & $-0.23^{*}$ & -0.29 & -0.16 \\
High & $-0.11^{\dagger}$ & -0.20 & -0.02 \\
\hline$R^{2}$ & 0.26 & & \\
$F$ & $69.97^{+}$ & & \\
$\Delta R^{2}$ & $0.01^{+}$ & & \\
$\Delta F$ & $10.45^{\dagger}$ & & \\
\hline
\end{tabular}

Notes: $\mathrm{CI}=\overline{\text { confidence interval; } L L=\text { lower limit; } U L=\text { upper limit; }{ }^{*} p<0.01,{ }^{\dagger} p<0.001 ; B=\text { regression }}$ coefficients.

Figure 3 indicated conditional effects of three levels of religiosity which were negative and significant (at $-1 \mathrm{SD}, b=-0.34, \mathrm{SE}=0.05, p<0.001$; at mean, $b=-0.23, \mathrm{SE}=0.04, p<0.001$; at $+1 \mathrm{SD}$, $b=-0.11, \mathrm{SE}=0.05, p<0.02$ ). The slope showed that married adults who reported a high level of religiosity maintained their quality of marital relationship despite of facing different kinds of family violence. Individuals with a higher level of religiosity had higher scores of marital quality across all levels of family violence in comparison to individuals with low levels of religiosity. Religiosity proved as a protective factor buffering the negative consequences of family violence by weakening or diminishing the negative association between family violence and marital quality.

Mediation analysis was carried out with PROCESS macro for SPSS (Hayes 2018). Table 4 showed total, direct, indirect and partial mediation effect of family violence on marital quality of Muslim married adults. $\mathrm{R}^{2}$ value of 0.01 indicates that self-compassion explained $1 \%$ of variance in marital quality with $F(1,597)=3.78, p<0.001$. $\mathrm{R}^{2}$ value of 0.29 indicates that $29 \%$ of variance in marital quality is explained by both self-compassion and family violence with $F(1,597)=122.45, p<0.001$ while total $\mathrm{R}^{2}$ of the model explains $14 \%$ of variation with $F(1,597)=99.31, p<0.001$.

Total effect emerged as statistically significant with, $t(600)=-9.97, p=0.001$ or between -0.40 and -0.27 with $95 \%$ confidence interval. Direct effect was statistically different from zero, $t(600)=-10.03$, $p=0.001$ with a $95 \%$ confidence interval from -0.37 to -0.25 . The direct effect of family violence $c^{\prime}=-0.31$, is the estimated difference in marital quality between two married adults experiencing the same level of self-compassion but who differ by one unit in their reported family violence. The coefficient is negative, meaning that the person who is facing a higher level of family violence but who equally uses the same level of sell-compassion is estimated to be 0.31 units lower in his/her reported marital quality. (see Figure 4). 


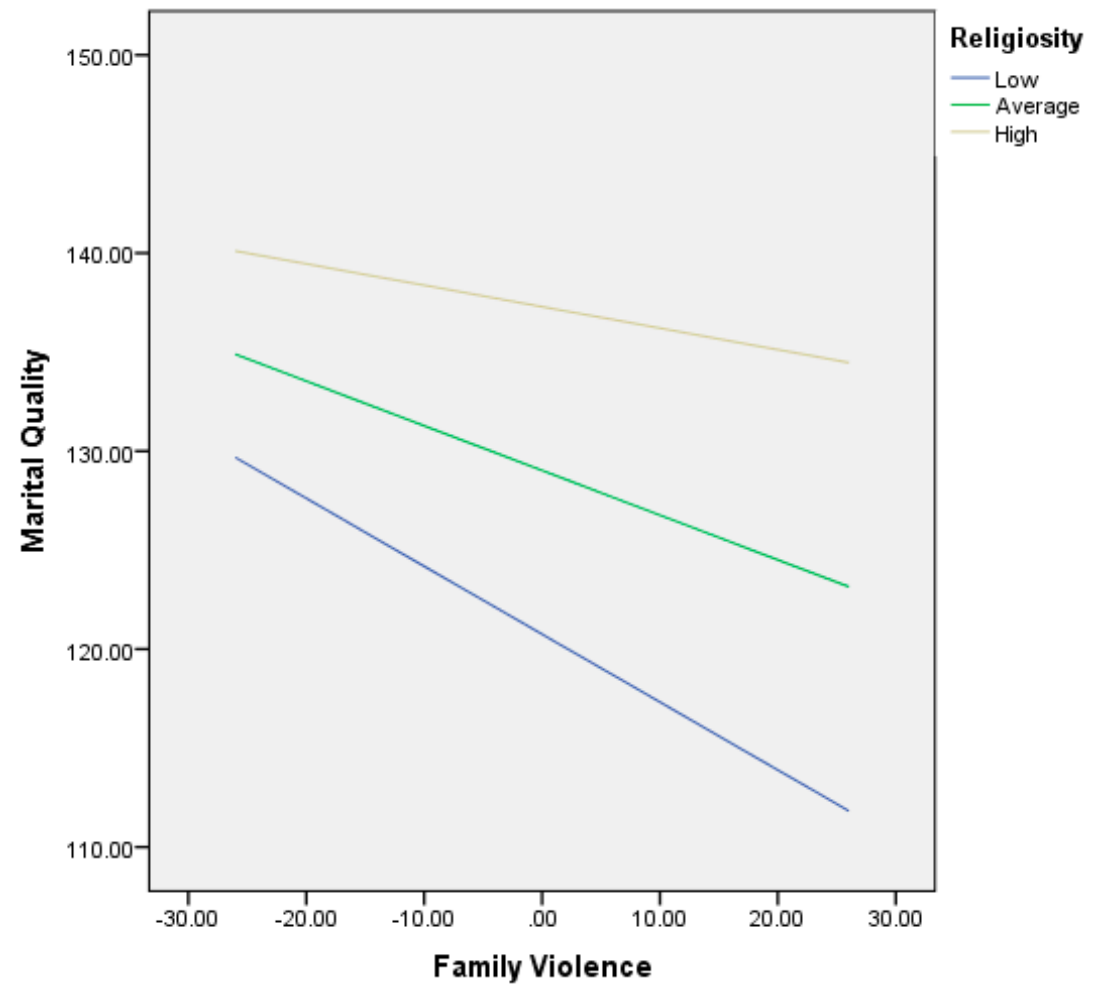

Figure 3. Graphical representation of moderating role of religiosity between family violence and marital quality.

Table 4. Model coefficients for self-compassion in relation with family violence and marital quality.

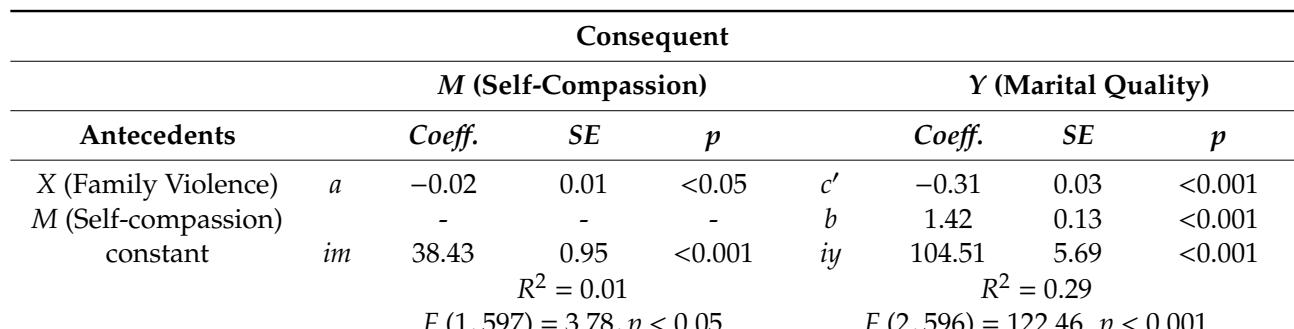

$a b($ Indirect effect $)=0.03,<0.001($ BootLLCI $=-0.05$, BootULCI $=-0.001)$

$C$ (total effect $)=-0.34(L L C I=-0.41, L L C I=-0.27)$

Notes: $a$ is effect of family violence on self-compassion; $b$ is effect of self-compassion on marital quality; $c^{\prime}$ is direct effect of family violence on marital quality; im is regression coefficient for moderator $(\mathrm{M})$ while iy is regression coefficient for outcome variable $(\mathrm{Y})$.

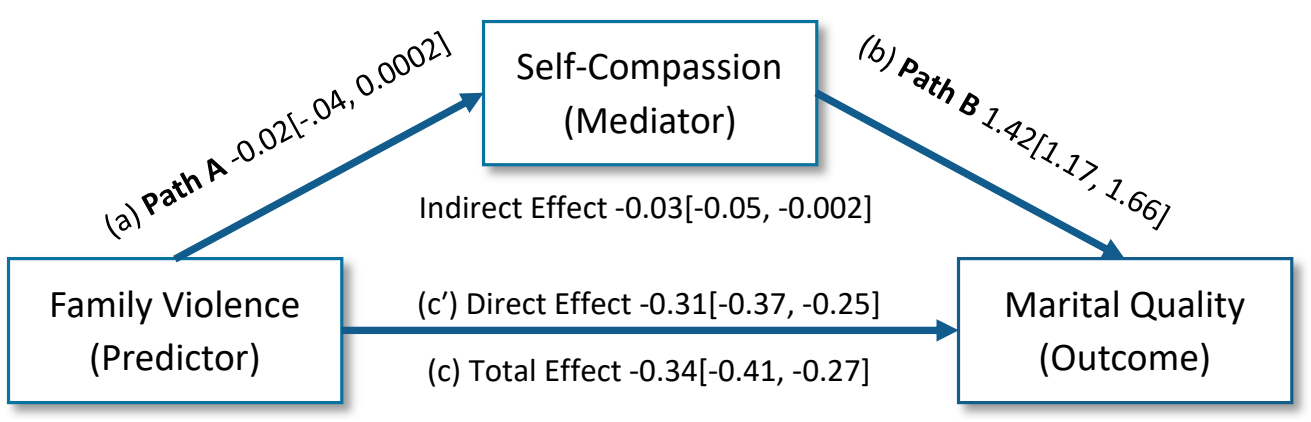

Figure 4. Simple mediation model for family violence study in the form of a statistical diagram. Notes: $a$ is the path A showing the effect of family violence on self-compassion; $b$ is the path B showing the effect of self-compassion on marital quality. 
Findings revealed that the indirect effect $(b=-0.03)$ is statistically different from zero $(-0.05$ to $-0.001)$, as revealed by $95 \%$ bootstrap confidence internal that is entirely above zero. This showed that two married adults, who differ by one unit in facing family violence, are estimated to differ by 0.03 units $(3 \%)$ in their reported marital quality as a result of more self-compassion, which in turn translated into greater marital quality (because $b$ is positive). This indirect effect confirmed the partial mediating effect of self-compassion in relation to family violence and marital quality of Muslim married adults. To put it simply, negative consequences of family violence were reduced when married adults were engaged more in self-compassion. The statistical diagram of mediation is presented below along with significant path coefficients

Results of Table 5 indicated significant gender differences in terms of religiosity $F(1,559)=8.57$, $p<0.01$, marital quality $F(1,559)=30.99, p<0.001$, and family violence $F(1,559)=121.41, p<0.001$. Furthermore, additional results of mean values revealed that men were more religious $(M=57.77$, $S D=7.62)$ as compared to married women $(M=55.80, S D=8.30)$ and men $(M=134.33, S D=23.12)$ also scored high on marital quality as compared to women $(M=123.63, S D=22.83)$. Married women $(M=77.77, S D=27.25)$ were facing more family violence as compared to men counterparts $(M=99.70$, $S D=21.21$ ). Moreover, there were no significant effects of gender regarding the use of self-compassion indicating that ratings from men and women participants were in general the same. Moreover, values of Partial Eta Square revealed that $7 \%$ of all variance in religiosity $\left(\eta^{2}=0.07\right), 15 \%$ variance in marital quality $\left(\eta^{2}=0.15\right)$ and $17 \%$ of all variance in family violence $\left(\eta^{2}=0.17\right)$ was accounted for by gender. Furthermore, values of observed power of all these variables showed from $83 \%$ to $100 \%$ probability for finding significant results.

Table 5. Multivariate analysis of variance for gender differences.

\begin{tabular}{ccccccccc}
\hline Source & $\begin{array}{c}\text { Dependent } \\
\text { Variable }\end{array}$ & SS & df & MS & $\boldsymbol{F}$ & $\boldsymbol{p}$ & $\eta^{2}$ & $\begin{array}{c}\text { Observed } \\
\text { Power }\end{array}$ \\
\hline \multirow{5}{*}{ Gender } & Religiosity & 554.29 & 1 & 554.29 & 8.57 & 0.01 & 0.07 & 0.83 \\
& Marital Quality & $16,323.73$ & 1 & $16,323.73$ & 30.99 & 0.001 & 0.15 & 1.00 \\
& Self-compassion & 21.31 & 1 & 21.31 & 0.52 & 0.47 & 0.01 & 0.11 \\
& Family Violence & $68,441.43$ & 1 & $68,441.43$ & 121.41 & 0.00 & 0.17 & 1.00 \\
\hline \multirow{5}{*}{ Error } & Religiosity & $38,627.12$ & 597 & 64.70 & & & & \\
& Marital Quality & $314,373.42$ & 597 & 526.59 & & & & \\
& Self-compassion & $24,665.37$ & 597 & 41.32 & & & & \\
& Family Violence & $336,541.21$ & 597 & 563.72 & & & & \\
\hline
\end{tabular}

\section{Discussion}

The present study examined the role of religiosity and self-compassion as moderating and mediating between family violence and marital quality in Pakistani married Muslims. Findings supported our first hypothesis that a negative relationship existed between family violence and marital quality (see Figure 1). Family violence is a serious health and emotional problem, which impedes the quality of life and life satisfaction (Cattaneo and Chapman 2013). Our results are aligned with Razera et al. (2016) who report violence in the marital relationship is associated with lower level of marital quality. The fact is, when a partner is mentally or physically tortured by his or her spouse then the overall appraisal of contentment with his or her marriage is severely affected and this overall appraisal of contentment with the relationship is the marital satisfaction which is the important component of marital quality (Kamp Dush et al. 2008, p. 212). It is also noted that, victims of family violence may develop mental health problems as well, such as emotional distress, depression and anxiety (Ellsberg et al. 2008), which further leads to dissatisfaction of relationship with spouses and impedes marital quality.

Results supported our hypothesis regarding the moderating role of religiosity between family violence and marital quality. Previous researchers confirmed our findings that religious values and religious attendance have positive associations with spousal commitment and marriage; hence leading 
to a quality relationship (Scot et al. 2008). Inclined towards religion, makes someone to forgive others for the sake of God and this attitude ultimately helps them to maintain their level of satisfaction in abusive relationships (Stafford 2016). For many believers, religion is not just a belief system but a code of life dominating personal and social life (David and Stafford 2013). In Islam, husband and wife both are supposed to guard each other's rights, as Al-Quran, allegorically says "They are clothing for you and you are clothing for them" (Qur'an 2:187). A husband is given a status of the "governor of the house" and a woman is guided to obey him and take care of the home. If he mistreats her, she is religiously guided to show patience to save the relationship and vice versa. Researchers found a positive effect of religiosity for marital quality promoting psychological wellbeing for survivors of family violence (Gillum et al. 2006), and women who attended a greater number of religious services were less likely to get divorced (Brown et al. 2008). Studies have also shown couples who had religiously involved spouses generally had significant positive impacts on various aspects of marriage and family life, such as marital quality, forgiveness, psychological wellbeing, self-esteem, life satisfaction and longevity (Marks 2005). It was also found that spouses who pray for each other and attend religious services together seem to experience better marital quality (Ellison et al. 2010).

Another hypothesis was also supported suggesting that self-compassion mediates the relationship between family violence and marital quality (see Figure 2), and weakens the relationship. In other words, negative consequences of family violence were reduced when there were high levels of self-compassion thus protecting marital quality. Protective factors do not necessarily eliminate the stressful events, rather they buffer impacts of stressful events, altering or reverting rise of negative effects (Masten et al. 2009).

Neff and Beretvas (2013) reported self-compassion as a good predictor of marital satisfaction among married couples. These researchers found that $85 \%$ of people reported suffering some form of domestic violence but when the quality and violence variables were examined separately, most couples $(\sim 67 \%)$ evaluated their relationship as average to very good because of self-compassion. Specifically, self-compassion has been found to be related to happiness, higher level of life-satisfaction and better emotional regulation (Barnard and Curry 2011).

The central concept of self-compassion would be to treat oneself well in times of difficulty (Neff 2003a); which is important especially for victims because usually they see themselves as the reason for any kind of violence faced at home. This helps them to lessen suffering, through patience, kindness, and understanding and recognize that all humans are imperfect and make mistakes. When we are mindful of our suffering and respond with kindness, remembering that suffering is a part of the shared human condition, we are able to cope with life's struggles and worse situations with greater ease (Neff et al. 2005).

Findings of the study showed gender differences in terms of religiosity, marital quality, and family violence while men and women were not different in the use of self-compassion. Findings showed that married women were facing more family violence as compared to married men. Literature supported our findings as 48 population-based studies from different parts of the world revealed the fact that $10 \%$ to $69 \%$ of the women reported having been physically attacked by their spouse during their lifetime (Krug et al. 2002). In Pakistan, the rate reported by married women during their live for physical violence was 32\%, 77\% for sexual abuse and $90 \%$ for psychological abuse (Ali et al. 2015). In patriarchal society, women experience partner violence and continue their abusive relationship because of their adherence to patriarchal norms and worse consequences. They often understood their situation as just part of the pain of being in a committed relationship and overlook the intensity of the situation to stay in this abusive relationship (Hayes 2014).

Gender differences were found in terms of marital quality. Mean values revealed that men were enjoying marital quality as compared to married women. In this collectivist culture, women are supposed to fulfill all the duties of family members including in-laws. However, despite all day working hard, she is not acknowledged for her time and efforts even by her husband and is taken for granted. She could not get along with and enjoy the company of the marital partner. This lack of 
pleasure and feelings of worthlessness reduces her marital quality. While on the other hand, in this male dominated society, men perceive themselves as superior and they think earning is their only duty. As they are fulfilling the basic needs of the wife, which is their only responsibility, they might feel more adjusted as compare to their counterparts. Bradbury et al. (2000) have supported our findings by arguing that quality of relationship is related to the capability for accomplishing daily demands and duties of marriage. Another study (Ackerman 2012) supported our findings by confirming that men can maintain quality of their marital relationship relatively easily as it would be easier for them to maintain loving relationship with aggressive women but for a women it is very difficult to live with an abusive husband. Similarly, as in a collectivistic society, men are given more privilege as a "son in-law" as they get more respect and social approval of the relationship from in laws as compared to married women (Marks et al. 2001). In Pakistani cultural context, blurred boundaries between the relationship with in-laws and spouses play an influencing role that may affects the quality of marital interactions between spouses.

Results revealed that married men were more religious than married women. Our findings were contrary to some of the previous research as in United States and in many other countries, women were intended to be more religious than men (Baker and Whitehead 2016; Schnabel 2016) and even some religious scholars have argued that women may be biologically predisposed to be more religious (Beit-Hallahmi 2014; Stark 2002). By contrast, in Muslim-majority countries gender gaps are less consistent as Muslim men are more likely to attend religious services than Muslim women in keeping with Islamic norms (Hackett et al. 2016). This religious involvement might be the reason that all married male participants continued their dissatisfactory marital relationship. Although religious participation does not seem to directly reduce problems of marriage life, a strong religious belief in marriage as a lifetime commitment has been linked to greater marital quality and stability (Heaton and Albrecht 1991). The fact is, the true spirit of the Islamic religion provides support and nurturance for patterns of family life instead of only focusing on traditional concepts of marital obligations. Similarly, performing religious activities like praying, recitation of Quran etc. is linked with marital satisfaction and is considered as one of the good coping strategies (Alsharif et al. 2011). Being more inclined towards religion and ascribing greater importance to religion in someone's life, makes someone forgive others for the sake of God, and this attitude ultimately helps them to maintain their adjustment and quality in abusive relationship (Stafford 2016). These results are also supporting our previous findings concerning why men scored high on marital quality as compared to women.

As far as self-compassion is concerned, no significant gender differences were found. Married men and women both were using the same level of self-compassion to deal with abusive relationships. Researchers found that as self-compassionate people accept themselves as imperfect individuals, this helps them to be more inclined to accept their partner's limitations and ignore their violent behaviors (Van Dam et al. 2011). Both married adults used self-compassion as a coping strategy to handle relationship problems demonstrating that this factor is a source of strength in times of struggle, which helps people cope with stress in a more powerful manner (Allen and Leary 2010).

\section{Conclusions}

\section{Limitations and Recommendations}

This evidence-based study suggests the healing effect of personal factors in married adults' life especially when facing different kinds of family violence. However, there may be few possible limitations of the study that should be interpreted with caution. The present study is correlational and may limit causality among variables. Furthermore, this study employed self-report measures, which might be susceptible to social desirability bias. Participants in our study were recruited from one province of Pakistan, for future research all provinces and territories should be included to extend generalizability of the present findings. For future studies, it would be more worthwhile to use a mixed-methods approach and experimental design as it would give a detailed picture of family 
violence and marital quality. In spite of these limitations, findings of the study added significant information to the growing body of knowledge about family violence. It also provides valuable guidance for the professionals to design interventions aimed at reducing the risk of family violence and increasing marital quality of Muslim married adults. Based on research findings, the following policy recommendations are suggested in order to control family violence against married adults:

1. To eradicate the problem from the root, one of the most important considerations is to change male-dominant ideologies which needs national level educational reforms. It is recommended to revise educational curriculums to make them gender sensitive and discourage discrimination. Furthermore, to reduce the risk of family violence on short term basis, there should be enough educational programs, both for women and men at the same levels.

2. Media should be warned to play a responsible role in terms of the aired content especially on family channels. Concerned authorities should intervene to promote women's role as leaders and equally respectable components of the society instead of portraying them as victims of violence. All electronic and print media should change the way they portray women.

3. All health professionals should be trained regarding this sensitive issue and government should have crisis centers and martial counseling centers in main health care centers like rural health centers, and main civil hospitals throughout the country.

4. Mental health practitioners might play an important role in designing culturally relevant interventions in clinical settings for married adults. In addition, Muslim scholars could play a strong role in nurturing the spiritual lives and improving the quality of the marital relationships for married adults when they seek spiritual counseling.

5. Although women are already working, the need to ensure more women are involved in formal services (such as police forces and courts of justice) and to arrange extensive training about the sensitivity of the topic for police officers to remove an important barrier to justice for victims of family violence.

6. Based upon observation, researcher would also highly suggest the Government of Pakistan to develop some recreational programs (especially in small town and cities) including family parks, and other entertaining places where women along with their family can enjoy and relax.

Author Contributions: Conceptualization, A.P and S.M.; methodology, A.P and S.M.; software, A.P.; validation, A.P and S.M.; formal analysis, A.P.; investigation, A.P and S.M.; resources, A.P.; data curation, A.P.; writing - original draft preparation, AP.; writing-review and editing, A.P and S.M visualization, A.P and S.M.; supervision, S.M.; project administration, A.P and S.M. All authors have read and agreed to the published version of the manuscript.

Funding: This research received no extra funding.

Conflicts of Interest: The authors declare no conflict of interest.

\section{References}

Ackerman, Jeffrey M. 2012. The relevance of relationship satisfaction and continuation to the gender symmetry debate. Journal of Interpersonal Violence 27: 3579-600. [CrossRef] [PubMed]

Ali, Parveen Azam, Paul B. Naylor, Elizabeth Croot, and Alicia O'Cathain. 2015. Intimate Partner Violence in Pakistan: A Systematic Review. Trauma Violence Abuse 16: 299-315. [CrossRef] [PubMed]

Allen, Ashley Batts, and Mark R. Leary. 2010. Self-Compassion, Stress, and Coping. Social and Personality Psychology Compass 4: 107-18. [CrossRef] [PubMed]

Alsharif, Naseer Z., Kimberly A. Galt, and Ted A. Kasha. 2011. Health and healing practices for the Muslim community in Omaha, Nebraska. Journal of Religion E Society 7: 150-68.

Aman, Jaffar, Jaffar Abbas, and Shaher Bano Nurunnabi. 2019. The Relationship of Religiosity and Marital Satisfaction: The Role of Religious Commitment and Practices on Marital Satisfaction among Pakistani Respondents. Behavioral Sciences 9: 30. [CrossRef] 
Austin, Philip, Jessica Macdonald, and Roderick MacLeod. 2018. Measuring Spirituality and Religiosity in Clinical Settings: A Scoping Review of Available Instruments. Religions 9: 70. [CrossRef]

Ayyub, Ruksana. 2000. Domestic Violence in the South Asian Muslim Immigrant Population in the United States. Journal of Social Distress and the Homeless 9: 237-48. [CrossRef]

Baker, Josheph O., and Andrew L. Whitehead. 2016. Gendering (non)religion: Politics, education, and gender gaps in secularity in the United States. Social Forces 94: 1623-45. [CrossRef]

Barnard, Laura K., and John F. Curry. 2011. Self-compassion: Conceptualizations, correlates, \& interventions. Review of General Psychology 15: 289-303.

Beit-Hallahmi, Benjamin. 2014. Psychological Perspectives on Religion and Religiosity. New York: Routledge.

Bradbury, Thomas N., Frank D. Fincham, and Steven R. H. Beach. 2000. Research on the nature and determinants of marital satisfaction: A decade in review. Journal of Marriage and the Family 62: 964-80. [CrossRef]

Brown, Edna, Terri L. Orbuch, and Jose A. Bauermeister. 2008. Religiosity and marital stability among black American and white American couples. Family Relations 57: 186-97. [CrossRef]

Burgess, Eaarnest Watson, and Harvey J. Locke. 1960. The Family: From Institution to Companionship, 2nd ed. New York: American Book Company.

Carvalho-Barret, André de, Júlia Sursis Nobre Ferro Bucher-Maluschke, Paulo César de Almeida, and Eros DeSouza. 2009. Human development and gender violence: A bioecological integration. Psicologia Reflexão e Crítica 22: 86-92.

Cattaneo, Lauren B., and R. Aliya Chapman. 2013. American Muslim Marital Quality: A Preliminary Investigation. Journal of Muslim Mental Health 7: 1-19.

Collins, Nancy L., and Stephen J. Read. 1990. Adult attachment, working models, and relationship quality in dating couples. Journal of Personality and Social Psychology 58: 644-63. [CrossRef] [PubMed]

David, Prabu, and Laura A. Stafford. 2013. Relational Approach to Religion and Spirituality in Marriage: The Role of Couples' Religious Communication in Marital Satisfaction. Journal of Family Issues 36: 232-49. [CrossRef]

Ellison, Christopher G., Amy M. Burdette, and W. Bradford Wilcox. 2010. The couple that prays together: Race and ethnicity, religion, and relationship quality among working-age adults. Journal of Marriage and Family 7: 963-75. [CrossRef]

Ellsberg, Mary, Henrica A. Jansen, Lori Heise, and Charlotte H. Watts. 2008. Intimate partner violence and women's physical and mental health in the WHO multi-country study on women's health and domestic violence: An observational study. Lancet 371: 1165-72. [CrossRef]

Gillum, Tameka L., Cris M. Sullivan, and Deborah L. Bybee. 2006. The importance of spirituality in the lives of domestic violence survivors. Violence against Women 12: 240-50. [CrossRef]

Hackett, Conrad, Caryle Murphy, David McClendon, and Anne Fengyan Shi. 2016. The Gender Gap in Religion around the World: Women Are Generally More Religious than Men, Particularly among Christians. Washington, DC: Pew Research Center.

Hayes, Sharon. 2014. Sex, Love and Abuse: Discourses on Domestic Violence and Sexual Assault. Basingstoke: Palgrave MacMillan.

Hayes, Andrew F. 2018. Introduction to Mediation, Moderation, and Conditional Process Analysis: A Regression-Based Approach. New York: The Guilford Press.

Hazan, Cindy, and Phillip R. Shaver. 1990. Love and work: An attachment theoretical perspective. Journal of Personality and Social Psychology 59: 270-80. [CrossRef]

Heaton, Tim B., and Stan L. Albrecht. 1991. Stable Unhappy Marriages. Journal of Marriage and the Family 53: 747-58. [CrossRef]

Henning, Kris, Angela R. Jones, and Robert Holdford. 2005. "I didn't do it, but if I did I had a good reason": minimization, denial, and attributions of blame among male and female domestic violence offenders. Journal of Family Violence 20: 131-39. [CrossRef]

Hood, Ralph R.W., Peter C. Hill, and Bernard Spilka. 2018. The Psychology of Religion: An Empirical Approach. New York: Guilford Publications.

Huber, Stefan. 2007. Are religious beliefs relevant in daily life? In Religion Inside and Outside Traditional Institutions. Edited by Heinz Streib. Lieden: Brill Academic Publishers, pp. 211-30.

Huber, Stefan, and Odilo W. Huber. 2012. The Centrality of Religiosity Scale (CRS). Religions 3: 710-24. [CrossRef] 
Janjani, Parisa, Lida Haghnazari, Farahnaz Keshavarzi, and Alireza Rai. 2017. The role of self-compassion factors in predicting the marital satisfaction of staff at Kermanshah University of medical sciences. World Family Medicine/Middle East Journal of Family Medicine 15: 1-6. [CrossRef]

Kamp, Dush Claire M., Miles G. Taylor, and Rhiannon A. Kroeger. 2008. Marital Happiness and Psychological Well-Being across the Life Course. Family Relation 57: 1-34. [CrossRef]

Karney, Benjamin R., and Bradbury Thomas Nelson. 1995. The longitudinal course of marital quality and stability: A review of theory, method, and research. Psychological Bulletin 118: 3-34. [CrossRef] [PubMed]

Khan, Azmat J., Tazeen S. Ali, and Ali K. Khuwaja. 2009. Domestic violence among Pakistani women: An insight into literature. Isra Medical Journal 1: 54-56.

Koenig, Michael A., Mian Bazle Hossain, Saifuddin Ahmed, and Khorshed Alam Mozumder. 2003. Individual and community-level determinants of domestic violence in rural Bangladesh. Demography 40: 269-88. [CrossRef]

Kousar, Rukhsana, and Ruhi Khalid. 2003. Relationship between conflict resolution strategies and perceived marital adjustment. Journal of Behavioral Sciences 14: 29-42.

Krug, Etienne G., James A. Mercy, Linda L. Dahlberg, Anthony B. Zwi, and Rafael Lozano. 2002. World Report on Violence and Health. Geneva: World Health Organization.

Langlais, Michael, and Siera Schwanz. 2017. Religiosity and Relationship Quality of Dating Relationships: Examining Relationship Religiosity as a Mediator. Religions 8: 187. [CrossRef]

Marks, Loren. 2005. How Does Religion Influence Marriage? Christian, Jewish, Mormon, and Muslim Perspectives. Marriage Family Review 38: 85-111. [CrossRef]

Marks, Stephen R., Huston Ted L., Johnson Elizabeth M., and Shelley M. MacDermid. 2001. Role balance among white married couples. Journal of Marriage and Family 63: 1083-98. [CrossRef]

Masten, Ann S., Cutuli J.J., Janette E. Herbers, and Marie-Gabrielle J. Reed. 2009. Resilience in Development. In Oxford Library of Psychology. Oxford Handbook of Positive Psychology. Edited by Shane J. Lopez and Charles R. Snyder. Oxford: Oxford University Press, pp. 117-31.

Mikulincer, Mario, and Phillip R. Shaver. 2003. The Attachment Behavioral System in Adulthood: Activation, Psychodynamics, and Interpersonal Processes. In Advances in Experimental Social Psychology. Edited by M. P. Zanna. New York: Elsevier Academic Press, vol. 35, pp. 53-152.

Neff, Kristin D. 2003a. Development and validation of a scale to measure self-compassion. Self and Identity 2: 223-50. [CrossRef]

Neff, Kristin D. 2003b. Self-Compassion: An alternative conceptualization of a healthy attitude toward oneself. Self and Identity 2: 85-102. [CrossRef]

Neff, Kristin D. 2011. Self-Compassion: Stop Beating Yourself Up and Leave Insecurity Behind. In The Role of Self-Compassion in Romantic Relationships. Edited by Kristin. D. Neff and S. Natasha Beretvas. New York: Morrow, vol. 12, pp. 1-21.

Neff, Kristin D., and S. Natasha Beretvas. 2013. The Role of Self-compassion in Romantic Relationships. Self and Identity 12: 78-98. [CrossRef]

Neff, kristin D., Ya-ping Hseih, and Kullaya Dejitthirat. 2005. Self-compassion, achievement goals, and coping with academic failure. Self and Identity 4: 263-87. [CrossRef]

Patricia, Tjaden, and Thoennes Nancy. 1998. The Prevalence, Incidence and Consequences of Violence against Women: Findings from the National Violence against Women. Survey Report No: NCJ 172837. Washington, DC: U.S. Department of Justice.

Perveen, Aisha, and Sadia Malik. 2019. Determinants and Outcomes of Family Violence among Married Adults of Punjab: Role of Mediating and Moderating Factors. Ph.D. dissertation, University of Sargodha, Sargodha, Pakistan.

Razera, Josiane, Clarisse Mosmann, and Falcke Denise. 2016. The interface between quality and violence in marital relationships. Paidéia Ribeirão Preto 26: 71-79. [CrossRef]

Schnabel, Landon. 2016. The gender pray gap: Wage labor and the religiosity of high-earning women and men. Gender E Society 30: 643-69.

Scot, M. Allgood, Sharon Harris, Linda Skogrand, and Thomas R. Lee. 2008. Marital Commitment and Religiosity in a Religiously Homogenous Population. Marriage \& Family Review 45: 52-67.

Stafford, Laura. 2016. Marital sanctity, relationship maintenance, and marital quality. Journal of Family Issues 37: 119-31. [CrossRef] 
Stark, Rodney. 2002. Physiology and faith: Addressing the "universal" gender difference in religious commitment. Journal for the Scientific Study of Religion 41: 495-507. [CrossRef]

Van Dam, Nicholas T., Sean C. Sheppard, John P. Forsyth, and Mitch Earleywine. 2011. Self-compassion is a better predictor than mindfulness of symptom severity and quality of life in mixed anxiety and depression. Journal of Anxiety Disorders 25: 123-30. [CrossRef] [PubMed]

Williams, Elizabeth Conway. 2015. Self-Compassion and Self-Forgiveness as Mediated by Rumination, Shame-Proneness, and Experiential Avoidance: Implications for Mental and Physical Health. Electronic Theses and Dissertations, Paper 2562. East Tennessee State University, Johnson City, TN, USA.

World Health Organization. 1996. Violence against Women. Geneva: WHO Consultation.

Zakar, Rubeena, Muhammad Z. Zakar, Rafael Mikolajczyk, and Alexander Krämer. 2012. Intimate partner violence and its association with women's reproductive health in Pakistan. International Journal of Gynecology E Obstetrics 117: 10-14.

(C) 2020 by the authors. Licensee MDPI, Basel, Switzerland. This article is an open access article distributed under the terms and conditions of the Creative Commons Attribution (CC BY) license (http://creativecommons.org/licenses/by/4.0/). 